\title{
Mesoporous carbon nanomaterials induced pulmonary surfactant inhibition, cytotoxicity, inflammation and lung fibrosis
}

\author{
Yunan Chen ${ }^{1,2, * *}$, Yi Yang ${ }^{3, * *}$, Bolong $\mathrm{Xu}^{4}$, Shunhao Wang ${ }^{1,2}$, Bin $^{\mathrm{Li}^{1}}{ }^{\text {, Juan }} \mathrm{Ma}^{1}$, Jie Gao ${ }^{1,2}$, \\ Yi Y. Zuo ${ }^{3, *}$, Sijin Liu $^{1,2, *}$
}

1. State Key Laboratory of Environmental Chemistry and Ecotoxicology, Research Center for Eco-Environmental Sciences, Chinese Academy of Sciences, Beijing 100085, China

2. University of Chinese Academy of Sciences, Beijing 100049, China

3. Department of Mechanical Engineering, University of Hawaii at Manoa, Honolulu, HI 96822, USA

4. Beijing Key Laboratory of Bioprocess Beijing Advanced Innovation Center for Soft Matter Science,

Engineering Beijing Laboratory of Biomedical Materials, Beijing University of Chemical Technology, Beijing 100029, China

\section{A R T I C L E I N F O}

\section{Article history:}

Received 31 March 2017

Revised 7 July 2017

Accepted 24 August 2017

Available online 8 September 2017

\section{Keywords:}

Mesoporous carbon nanomaterials

Environmental exposure

Pulmonary surfactant

Inflammation

Fibrosis

\begin{abstract}
A B S T R A C T
Environmental exposure and health risk upon engineered nanomaterials are increasingly concerned. The family of mesoporous carbon nanomaterials (MCNs) is a rising star in nanotechnology for multidisciplinary research with versatile applications in electronics, energy and gas storage, and biomedicine. Meanwhile, there is mounting concern on their environmental health risks due to the growing production and usage of MCNs. The lung is the primary site for particle invasion under environmental exposure to nanomaterials. Here, we studied the comprehensive toxicological profile of MCNs in the lung under the scenario of moderate environmental exposure. It was found that at a low concentration of $10 \mu \mathrm{g} / \mathrm{mL}$ MCNs induced biophysical inhibition of natural pulmonary surfactant. Moreover, MCNs at similar concentrations reduced viability of J774A.1 macrophages and lung epithelial A549 cells. Incubating with nature pulmonary surfactant effectively reduced the cytotoxicity of MCNs. Regarding the pro-inflammatory responses, MCNs activated macrophages in vitro, and stimulated lung inflammation in mice after inhalation exposure, associated with lung fibrosis. Moreover, we found that the size of MCNs played a significant role in regulating cytotoxicity and pro-inflammatory potential of this nanomaterial. In general, larger MCNs induced more pronounced cytotoxic and pro-inflammatory effects than their smaller counterparts. Our results provided valuable information on the toxicological profile and environmental health risks of MCNs, and suggested that fine-tuning the size of MCNs could be a practical precautionary design strategy to increase safety and biocompatibility of this nanomaterial. (C) 2017 The Research Center for Eco-Environmental Sciences, Chinese Academy of Sciences. Published by Elsevier B.V.
\end{abstract}

\footnotetext{
* Corresponding authors. E-mails: yzuo@hawaii.edu (Yi Y. Zuo), sjliu@rcees.ac.cn (Sijin Liu).

** These authors equally contribute to this work.
} 


\section{Introduction}

Mesoporous carbon nanomaterials (MCNs) possess desirable physicochemical properties, including chemical stability, high electric and thermal conductivity and strong optical absorption feature (Xu et al., 2014). Moreover, MCNs possess a well-organized pore network, with the pore size usually ranging from 1.5 to $10 \mathrm{~nm}$ (Xu et al., 2014). This intricate porosity generates a high surface area and high pore volume, which endow this material with enhanced capability in storing energy and chemotherapeutic drugs (Kim et al., 2008; Vallet-Regí et al., 2007). Owing to these pronounced physicochemical properties, MCNs have been squeezed into the cutting edge of nanotechnology. Studies have revealed promising applications of MCNs in a large array of biomedical branches, such as cancer nanotheranostics and biosensing. The development of MCN-centered biomedicine requires in-depth understanding about its biocompatibility, biosafety and potential health risks. Compared to other carbon nanomaterials, the current understanding on the biocompatibility and health effects of MCNs is rather limited. Thus, sufficient insights into its toxicity profile become a prerequisite for further development of MCN-based applications.

In general, the respiratory system is most susceptible to environmental exposure to airborne nanomaterials. Although relatively large particles can be cleared by the mucociliary escalator in airway, nanomaterials such as MCNs may penetrate deeply into the lung. The entire air-water interface of the lung is coated with an adsorbed pulmonary surfactant film (Zuo et al., 2008). The pulmonary surfactant is composed of approximately $90 \%$ phospholipids and 10\% surfactant-associated proteins by weight (Lopez-Rodriguez and Pérez-Gil, 2014). The major physiological function of the pulmonary surfactant is to act as the first-line host defense against inhaled particles and pathogens, and to reduce the alveolar surface tension against lung collapse. Deficiency or dysfunction of the pulmonary surfactant leads to pathological pulmonary conditions such as the respiratory distress syndrome and acute lung injury (Lewis and Veldhuizen, 2003).

The pulmonary surfactant film functions as the initial biological barrier against inhaled particles (Fan et al., 2011; Hu et al., 2013). Consequently, interacting with the inhaled particles may adversely affect the biological function of the pulmonary surfactant film. Accumulating evidence showed that various engineered nanomaterials inhibited the biological function of the pulmonary surfactant, i.e., abolished its ability of reducing surface tension to near-zero values (Beck-Broichsitter et al., 2011; Fan et al., 2011; Sachan et al., 2012). It was found that the extent of surfactant inhibition caused by the inhaled nanomaterials largely depended on their physicochemical properties, such as the chemical, size, shape, surface area, hydrophobicity, and surface charge of the nanomaterials (Beck-Broichsitter et al., 2011; Fan et al., 2011; Sachan et al., 2012). After interaction and translocation across the pulmonary surfactant film, inhaled nanomaterials are in direct contact with the alveolar epithelium cells and macrophages, posing detrimental effects on cells and even causing inevitable cell death (Xia et al., 2016). Meanwhile, some invaded particles can be phagocytosed by resident macrophages (Xia et al., 2016). Therefore, macrophages form a group of important sentinels to sense and engulf invading particles (Wynn et al., 2013). Macrophages are also activated through sensing molecules to enhance pro-inflammatory responses by secreting inflammatory cytokines and recruiting additional inflammatory leukocytes (Sandberg et al., 2012).

In this study, we systematically evaluated the biocompatibility and potential toxicity associated with MCNs of various sizes. We first evaluated the potential adverse biophysical effect of MCNs on natural pulmonary surfactant. Then, we studied the toxic effects of MCNs through investigating cell viability, cellular uptake, oxidative stress, pro-inflammatory responses in vitro and in vivo, and lung fibrosis in mice. We found that MCNs caused pulmonary surfactant inhibition and induced significant cytotoxicity to macrophages. This study opened a new avenue to understand the adverse biological effects and environmental health risks of MCNs.

\section{Materials and methods}

\subsection{Synthesis and characterization of MCNs}

Zinc nitrate hexahydrate $\left(\mathrm{Zn}\left(\mathrm{NO}_{3}\right)_{2} \cdot 6 \mathrm{H}_{2} \mathrm{O}\right)$, 2-methylimidazole, cetyltrimethylammonium bromide (CTAB), tetraethyl orthosilicate (TEOS), and PEG-Vitamin E (PEG-VE) were purchased from Sigma (USA). All reagents were in the analytical grade and were used without further purification. In brief, $\mathrm{Zn}\left(\mathrm{NO}_{3}\right)_{2} \cdot 6 \mathrm{H}_{2} \mathrm{O}$ ( 3 amounts at 16, 24 and $32 \mathrm{mmol}$ were individually used for different sizes) was dissolved in 225, 300, and $450 \mathrm{~mL}$ methanol, respectively, and 2-methylimidazole (67.5, 101.25 and $135 \mathrm{mmol})$ was thereafter added into methanol accordingly. Then, two methanol solutions were mixed, and stirred for $2 \mathrm{hr}$ at $25^{\circ} \mathrm{C}$. For the intermediate sized MCNs (I-MCNs), $225 \mathrm{~mL}$ methanol solution containing $16 \mathrm{mmol} \mathrm{Zn}\left(\mathrm{NO}_{3}\right)_{2} \cdot 6 \mathrm{H}_{2} \mathrm{O}$ and $67.5 \mathrm{mmol}$ 2-methylimidazole were individually added into the above solution. For the largest sized MCNs (L-MCNs), $150 \mathrm{~mL}$ methanol solution containing $8 \mathrm{mmol} \mathrm{Zn}\left(\mathrm{NO}_{3}\right)_{2} \cdot 6 \mathrm{H}_{2} \mathrm{O}$ and $33.75 \mathrm{mmol}$ 2-methylimidazole were accordingly added into the above solution. For the smallest sized MCNs (S-MCNs), no solution was added. Finally, imidazolate framework (ZIF-8), a carbon precursor, was obtained through centrifugation and washing. Next, the carbon precursors were dispersed in $240 \mathrm{~mL}$ methanol ( $\mathrm{pH} 11$, adjusted by $\mathrm{NaOH})$, and the CTAB solution $(0.8 \mathrm{mmol} / \mathrm{L})$ was added. TEOS (1.2 mL) was then added dropwise into the above mixed solution, and the resulting solution was stirred for $0.5 \mathrm{hr}$. The carbon precursor@mSiO ${ }_{2}$ was separated by centrifugation, and washed with ethanol. Afterwards, the carbon precursor@ $\mathrm{mSiO}_{2}$ was pyrolyzed for $2 \mathrm{hr}$ under $\mathrm{N}_{2}$ atmosphere at $800^{\circ} \mathrm{C}$, and was cooled naturally to room temperature. The samples were added into $4 \mathrm{~mol} / \mathrm{L} \mathrm{NaOH}$ solution to remove the $\mathrm{mSiO}_{2}$ shell. The obtained samples were centrifuged and washed with water until the $\mathrm{pH}$ of supernatant reached 7.0. Finally, all samples were modified by PEG-VE (1 kD). The morphology and size of MCNs were characterized by $\mathrm{H}-7500$ electron microscope (TEM) and SU8020 scanning electron microscope (SEM). The zeta potential and hydrodynamic diameter were measured using dynamic light scattering (DLS, Malvern, UK). In addition, carbon black (CB), purchased from Macklin, was used a reference carbonaceous material in the current study. 


\subsection{Pulmonary surfactant}

Infasurf (calfactant) was a gift from ONY, Inc. (Amherst, NY, USA). It was a modified natural surfactant prepared from lung lavage of newborn calves by centrifugation and organic solvent extraction. Infasurf contained all hydrophobic components of the bovine natural surfactant (Zhang et al., 2011). Hydrophilic surfactant proteins (SP-A and SP-D), however, were removed during the extraction process. Infasurf was stored frozen in sterilized vials with an initial concentration of $35 \mathrm{mg}$ of total phospholipids per milliliter. For all trials, Infasurf was diluted to a phospholipid concentration of $1 \mathrm{mg} / \mathrm{mL}$ with a saline buffer of $0.9 \% \mathrm{NaCl}, 1.5 \mathrm{mmol} / \mathrm{L} \mathrm{CaCl}$, and $2.5 \mathrm{mmol} / \mathrm{L}$ HEPES, adjusted to $\mathrm{pH}$ 7.0. The saline buffer was made with Milli-Q ultrapure water (Millipore, Billerica, MA, USA) with a resistivity greater than $18 \mathrm{M} \Omega / \mathrm{cm}$ at room temperature.

\subsection{Constrained drop surfactometry}

Surfactant inhibition under physiologically relevant conditions was conducted with constrained drop surfactometry (CDS, BioSurface Instruments, HI, USA). CDS was a droplet-based surface tensiometry technique, newly developed for in vitro assessing biophysical properties of pulmonary surfactant (Valle et al., 2015). CDS used the air-water interface of a sessile drop ( $3 \mathrm{~mm})$, constrained on a carefully machined drop pedestal with a sharp knife-edge, to accommodate the adsorbed surfactant film. Hence, the CDS required only a minute sample size of less than $20 \mu \mathrm{L}$ for assessing biophysical properties of the pulmonary surfactant. Also owing to system miniaturization, the CDS permitted a precise control of physiological conditions using an environmental control chamber. To simulate breathing, the adsorbed surfactant film could be compressed and expanded at a physiologically relevant rate and compression ratio. The surface tension and surface area were determined photographically from the shape of the droplet using axisymmetric drop shape analysis (ADSA) (Yu et al., 2016).

Specifically, Infasurf was diluted to a concentration of $1 \mathrm{mg} / \mathrm{mL}$ and mixed with MCNs to a final particle concentration of $10 \mu \mathrm{g} / \mathrm{mL}$, i.e., $1 \%$ by weight of total phospholipids in Infasurf. This MCNs concentration was selected corresponding to the lower end of MCNs concentrations tested in cytotoxicity assays, with more relevance to environmental exposure (Xia et al., 2016). Mixtures of MCNs and Infasurf were incubated at $37^{\circ} \mathrm{C}$ for $1 \mathrm{hr}$ prior to the biophysical assay. A droplet $(\sim 16 \mu \mathrm{L})$ of the MCN-Infasurf mixture was dispensed onto the CDS drop pedestal. After drop formation, the surface tension was recorded and found to quickly decrease to an equilibrium value of approximately $22 \mathrm{mN} / \mathrm{m}$, indicating adsorption of surfactant films at the air-water interface. Once adsorption was completed, the surfactant film was compressed and expanded at a rate of $3 \mathrm{sec}$ per cycle with a compression ratio controlled at no more than $25 \%$ of the initial surface area to simulate normal tidal breathing (Bachofen et al., 1987). To obtain the absolute minimum surface tension of the surfactant film, overcompression at $30 \%$ and $40 \%$ compression ratios was also tested. At least ten continuous compression-expansion cycles were studied for each droplet. All simulations were conducted under well-controlled physiological conditions $\left(37^{\circ} \mathrm{C}\right.$ and $100 \%$ relative humidity) for at least 3 times. Surface activity was quantified with the minimum surface tension $\left(\gamma_{\min }\right)$ at the end of compression, and the average isothermal film compressibility $(\kappa), \kappa=\frac{1}{A}\left(\frac{\partial A}{\partial \gamma}\right)_{T}$ (where, $A$ is the surface area, $\gamma$ is the surface tension, $T$ is the temperature) during both the compression and expansion processes.

\subsection{Cell culture}

Mouse monocyte/macrophage cell line J774A.1 and human adenocarcinomic alveolar basal epithelial cell line A549 were purchased from the Shanghai Cell Bank of Type Culture Collection of Chinese Academy of Sciences. Cells were routinely cultured in Dulbecco's Modified Eagle's Medium (DMEM), supplemented with $10 \%$ fetal bovine serum (FBS, Gibco, MA, USA) and $100 \mathrm{U} / \mathrm{mL}$ penicillin/streptomycin (Gibco, MA, USA) at $37^{\circ} \mathrm{C}$ with $5 \% \mathrm{CO}_{2}$.

\subsection{Cell viability assay}

To assess the cell viability post MCN treatment, cells were first seeded at a density of $1 \times 10^{4}$ per well in 96-well plates (Corning Inc., NY, USA) at $37^{\circ} \mathrm{C}$ overnight. Further, cells were exposed to MCNs at various concentrations for $24 \mathrm{hr}$. Thereafter, cell viability was examined with a commercial CCK8 cell proliferation and cytotoxicity assay kit following the instructions from the manufacturer (Dojindo, Japan).

\subsection{Cellular reactive oxygen species (ROS) assay}

For the measurement of cellular ROS production, cells were first pre-incubated with $10 \mu \mathrm{mol} / \mathrm{L}$ dichlorofluorescein-diacetate (DCF-DA, Sigma, MO, USA) for $30 \mathrm{~min}$ and were then treated with MCNs at various concentrations. After treatment at 1 and $6 \mathrm{hr}$, DCF fluorescence was recorded by flow cytometry (FACS), as described previously (Qu et al., 2013).

\subsection{Lactate dehydrogenase (LDH) release assay}

Plasma membrane permeability was determined by the extracellular LDH leakage with a commercial kit from Promega (WI, USA). Briefly, after cellular treatment with MCNs at various concentrations for $24 \mathrm{hr}$, culture medium was collected and was centrifuged at 12,000 $\times \mathrm{g}$, and the supernatants were subjected to the measurement of LDH release following the manufacture's instruction.

\subsection{Intracellular characterization of MCNs by TEM}

To characterize intracellular MCNs, TEM analysis was performed. In brief, J774A.1 cells were gently washed with PBS after MCN treatment, and were then fixed with $2.5 \%$ glutaraldehyde. The fixed cells were afterwards embedded with epoxy resin. Ultrathin cell specimens $(70 \mathrm{~nm})$ were prepared and placed on grids, and were stained with $1 \%$ lead citrate and $0.5 \%$ uranyl acetate, followed by examination using a high-resolution JEOL JEM 2010F TEM (Hitachi Scientific Instruments, Japan).

\subsection{RT-qPCR analysis}

Total cellular RNAs were isolated from cells post treatment using Trizol reagent following the manufacturer's instruction 
(Invitrogen, MA, USA). Thereafter, $2 \mu \mathrm{g}$ total RNAs for each sample were reverse-transcribed into cDNAs with M-MLV reverse transcriptase (Promega, WI, USA). The relative expression levels of interest genes were then measured with SYBR Green qPCR mix (Promega Inc., USA) on an Mx3005P PCR machine (Bio-Rad). GAPDH was used as an internal control for normalization. The primer sequences are shown as follows, IL-6, forward: 5'-GTCTTGGCCGAGGACTAAGG-3'; reverse: 5'-T ACTCGGCAAACCTAGTGCG-3'; TNF- $\alpha$, forward: $5^{\prime}$-GACAAGGC TGCCCCGACTA-3'; reverse: 5'-TTTCTCCTGGTATGAGATAGCA AATC-3'; GAPDH, forward: 5'-AAGGTCATCCCAGAGCTG-3'; reverse, 5'-GCCATGAGGTCCACCACCCT-3'.

\subsection{Animal experimentation}

Seven weeks old BALB/c female mice were obtained from the Vital River Laboratory Animal Technology Co. Ltd., Beijing, China. All animal experimental procedures were approved by the Animal Ethics Committee at the Research Center for Eco-Environmental Sciences, Chinese Academy of Sciences. Following the previous protocol (Wang et al., 2011, 2012), pharyngeal aspiration was used to introduce MCNs to the mouse lung. Briefly, anesthetized mice were instilled at the position of the back tongue with MCNs at $50 \mathrm{mg} / \mathrm{kg}$ body weight. Mice were sacrificed 1 and 7 days after material administration. Blood was collected for assessment of inflammatory cytokines in sera, and lung specimens were saved for histological examination. The control mice received saline only.

\subsection{Complete blood count $(\mathrm{CBC})$ of peripheral blood}

When mice were sacrificed, $20 \mu \mathrm{L}$ fresh blood was immediately diluted in $2 \mathrm{~mL}$ diluent buffer provided by the manufacturer. CBC analysis was performed on a MEK-7222K automated hematology analyzer (Nihon Kohden, Japan).

\subsection{Hematoxylin-Eosin (H\&E) staining, Masson's trichrome} staining and immunohistochemical staining

Tissue specimens were immediately fixed into $10 \%$ formalin in PBS when mice were sacrificed post MCN administration. Tissue specimens were embedded in a paraffin blocks, and were then sliced into $5 \mu \mathrm{m}$ thick sections onto slides. H\&E and Masson's trichrome staining were carried out according to the standard protocols, as previously described (Xu et al., 2016). The stained slides were examined and imaged with an Axio Scope A1 optical microscope (Carl Zeiss, Inc., Germany). Immunohistochemical staining of alpha-smooth muscle actin ( $\alpha$-SMA) was carried out using an antibody from Servicebio Inc., China (1:1000) following the standing protocol.

\subsection{Cytokine determination}

The concentrations of inflammatory cytokine TNF- $\alpha$ were assayed in sera from MCN-treated mice using ELISA kits according to the manufacturer's instructions (GenStar, China).

\subsection{Statistical analysis}

Independent t-test and one-way ANOVA test were used to analyze experimental data. Data were shown in mean \pm standard derivation. Statistical significance was determined with $\mathrm{P}$ value less than 0.05 (namely $p<0.05$ ) in the current study.

\section{Results and discussion}

\subsection{Characterization of MCNs}

We prepared the MCNs through carbonization of carbon precursor, protected by mesoporous silica shell. The $\mathrm{mSiO}_{2}$ shell coating on the surface carbon precursor effectively prevented aggregation of MCNs during high temperature pyrolysis. As shown in Fig. 1a, the SEM images revealed that monodisperse MCNs were obtained. The size distribution analysis on the basis of SEM data showed that the average diameter was 93, 111 and $144 \mathrm{~nm}$ for the smallest sized MCNs (S-MCNs), the intermediate sized MCNs (I-MCNs) and the largest sized MCNs (L-MCNs), respectively (Fig. 1a, $p<0.05$ ). The difference in diameter for $\mathrm{MCN}$ samples was also confirmed by TEM analysis (Fig. 1b). Furthermore, DLS analysis manifested a similar size increase from S-MCNs to I-MCNs and L-MCNs in water and culture medium with $10 \%$ FBS (Fig. 1c, $p<0.05$ ). Moreover, all sizes in culture medium with $10 \%$ FBS became slightly smaller than those in water, indicating that MCN particles were better dispersed in culture medium with the aid of proteins in FBS (Allouni et al., 2009; Maiorano et al., 2010). The zeta-potential data showed that all MCN samples were negatively charged (Fig. 1d). Collectively, these data demonstrated that we have successfully prepared MCN samples with different sizes.

\subsection{MCNs induced surfactant inhibition}

Fig. 2 compared typical compression-expression cycles of pure Infasurf with the addition of $1 \%$ by weight MCNs at 3 different sizes, i.e., S-MCNs, I-MCNs and L-MCNs. Reproducibility of these cycles can be found in Fig. S1. Also shown in Fig. 2 was the result of Infasurf mixed with $1 \%$ by weight carbon black (CB) used as a reference carbonaceous material. Experimental conditions used to obtain these cycles fully mimicked the physiological conditions, especially by controlling the area reduction during film compression (i.e., the so-called compression ratio) to no more than 25\% (Bachofen et al., 1987). It can be seen that the addition of $1 \%$ by weight MCNs at 3 different sizes all increased the minimum surface tension at the end of compression. The MCNs also increased the area enclosed in the hysteresis loop between compression and expansion curves. All these phenomena indicate surfactant inhibition (Schürch et al., 1992, 1998). The degree of surfactant inhibition caused by the MCNs was comparable to that of the $\mathrm{CB}$ at the same concentration.

To quantify the degree of surfactant inhibition caused by MCNs of 3 different sizes, Fig. 3 showed the statistical analyses of the isothermal film compressibility $(\kappa)$ during the film compression and expansion processes of the dynamic cycling demonstrated in Fig. 2. Film compressibility measures the "hardness" of a two-dimensional film. A low $\kappa$ indicates a "hard" film, while a high $\kappa$ indicates a "soft" film. A good pulmonary surfactant film should have a "soft-yet-strong" attribute (Zuo and Possmayer, 2007; Zuo et al., 2008). Upon film compression during exhalation, the surfactant film should have a low $\kappa$, thus decreasing alveolar 
a

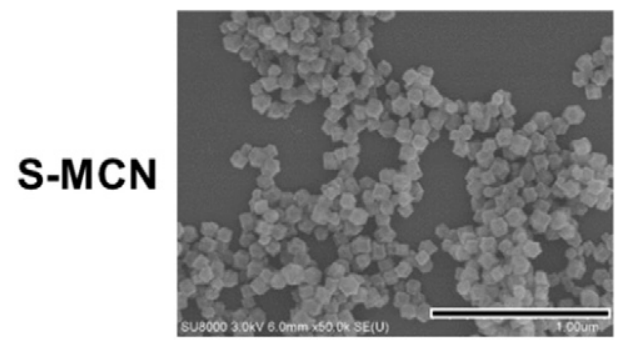

I-MCN

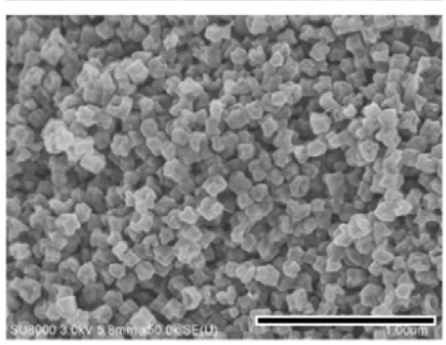

L-MCN

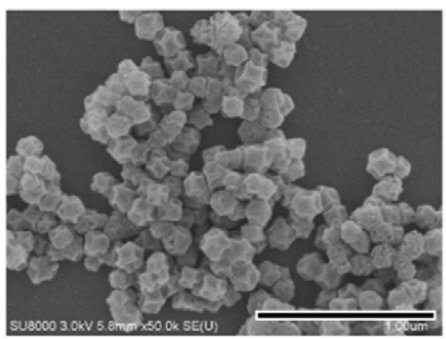

C

\begin{tabular}{|c|c|c|}
\hline \multirow{2}{*}{ Group } & \multicolumn{2}{|c|}{ Diameter (nm) } \\
\cline { 2 - 3 } & In water & In medium \\
\hline S-MCN & $157.3 \pm 2.8$ & $105.7 \pm 4.0$ \\
\hline I-MCN & $193.0 \pm 1.1$ & $122.3 \pm 5.0$ \\
\hline L-MCN & $266.8 \pm 3.4$ & $165.3 \pm 3.8$ \\
\hline
\end{tabular}

b
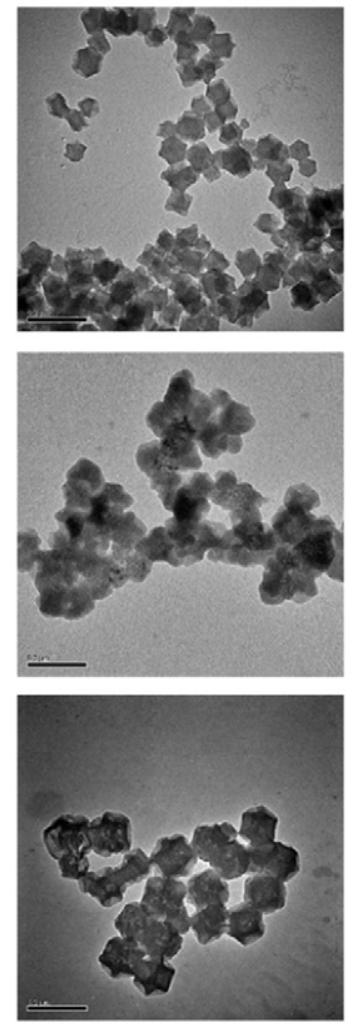

d

\begin{tabular}{|c|c|c|}
\hline \multirow{2}{*}{ Group } & \multicolumn{2}{|c|}{ Zeta-potential $(\mathrm{mV})$} \\
\cline { 2 - 3 } & In water & In medium \\
\hline S-MCN & $-10.0 \pm 0.6$ & $-26.3 \pm 2.8$ \\
\hline I-MCN & $-14.3 \pm 0.7$ & $-17.1 \pm 1.0$ \\
\hline L-MCN & $-15.8 \pm 0.1$ & $-19.3 \pm 1.8$ \\
\hline
\end{tabular}

Fig. 1 - Physicochemical characterization of mesoporous carbon nanomaterial (MCN) samples. (a) Representative scanning electron microscope (SEM) images of S-MCNs, I-MCNs and L-MCNs. Original magnification, $\times 120,000$. The scale is $1 \mu \mathrm{m}$. (b) TEM images of S-MCNs, I-MCNs and L-MCNs. Original magnification, $\times 100,000$. The scale is $0.2 \mu \mathrm{m}$. (c) Hydrodynamic diameters of S-MCNs, I-MCNs and L-MCNs in water and in cell culture medium with $10 \%$ FBS ( $n=3$ ). (d) Zeta potentials of S-MCNs, I-MCNs and L-MCNs in water and in cell culture medium with $10 \%$ fetal bovine serum (FBS) $(n=3)$.

surface tension to low values with limited area reduction; while upon film expansion during inhalation, the surfactant film should have a high $\kappa$, thus only increasing $\gamma$ to a limited value. Therefore, $\kappa$ is commonly used to evaluate surfactant inhibition (Valle et al., 2014, 2015).

As shown in Fig. 3, all 3 different sized MCNs, at a very low concentration of $10 \mu \mathrm{g} / \mathrm{mL}$, increased $\kappa$ of the Infasurf film during compression ( $\left.\kappa_{\text {comp }}\right)$ and decreased $\kappa$ during expansion $\left(\kappa_{\text {exp }}\right)$, indicating surfactant inhibition. However, no statistically significant differences were found in the inhibition potential between 3 different sized MCNs. Again, the degree of surfactant inhibition caused by the 3 different sized MCNs was found to be comparable to the CB $(p>0.05)$.

The minimum surface tension $\left(\gamma_{\min }\right)$ is another commonly used parameter to evaluate surfactant inhibition. However, $\gamma_{\text {min }}$ is also a function of the film compression ratio (CR). The higher the CR, the lower the $\gamma_{\text {min }}$. Hence, in addition to the physiologically relevant $25 \%$ compression, we also conducted dynamic cycling experiments with supraphysiological levels of film compression, i.e., at $30 \%$ and $40 \%$ CRs. (Representative results are shown in Fig. S1.) As shown in Fig. 4, with the physiologically relevant $25 \% \mathrm{CR}$, the $\gamma_{\min }$ of pure Infasurf 


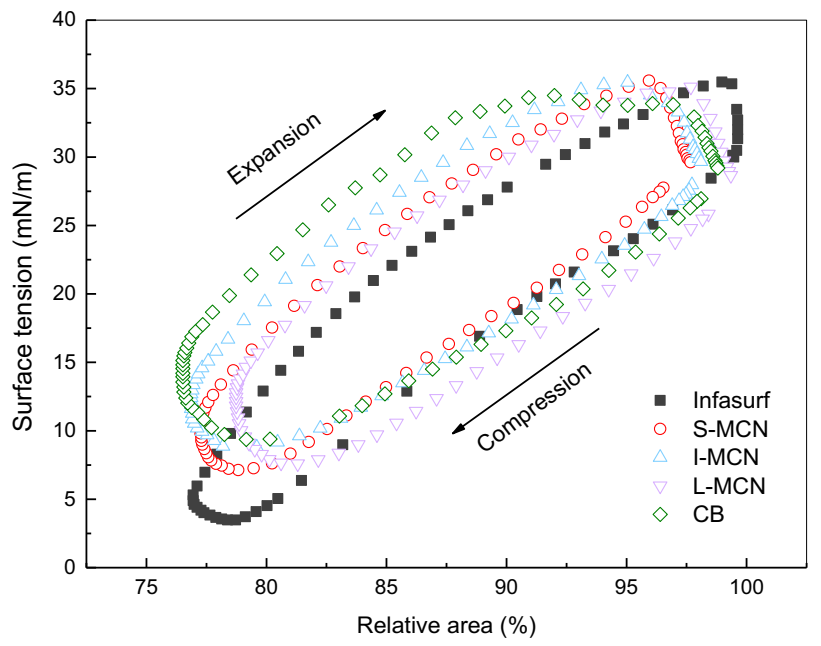

Fig. 2 - Comparison of dynamic cycles of pure Infasurf ( $1 \mathrm{mg} / \mathrm{mL}$ ) with $1 \%$ by weight MCNs, and carbon black (CB). These cycles simulated the compression-expansion cycles of lung surfactant films during normal tidal breathing: $37^{\circ} \mathrm{C}, 100 \%$ relative humidity ( $\mathrm{RH}), 3$ sec/cycle, and a maximum $25 \%$ area reduction upon film compression.

reached $3.5 \mathrm{mN} / \mathrm{m}$. However, after exposure to $1 \%$ by weight MCNs of 3 different sizes, the $\gamma_{\min }$ increased above $7.1 \mathrm{mN} / \mathrm{m}$, more than double that of the pure Infasurf. Increasing the $\mathrm{CR}$ from $25 \%$ to $40 \%$ further decreased the $\gamma_{\min }$ of pure Infasurf from 3.5 to $1.2 \mathrm{mN} / \mathrm{m}$. Increasing the $\mathrm{CR}$ also reduced the $\gamma_{\min }$ of Infasurf mixed with MCNs. However, $\gamma_{\min }$ of the mixtures was still higher than that of the pure Infasurf.

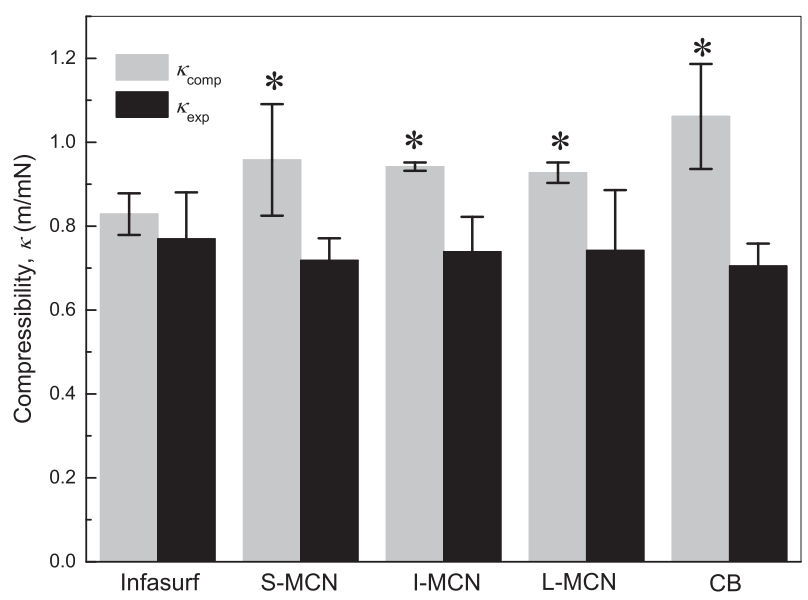

Fig. 3 - Statistical analysis of the film compressibility during compression ( $\kappa_{\text {comp }}$ ) and expansion ( $\left.\kappa_{\text {exp }}\right)$ processes (the 10th cycle). A good lung surfactant film should have a low compressibility ( $\kappa_{\text {comp }}$ ) and a high expandability ( $\left.\kappa_{\text {exp }}\right)$. It can be seen that all MCNs and CB (at $1 \%$ by weight of Infasurf) increase $\kappa_{\text {comp }}$ and decrease $\kappa_{\text {exp }}$ of Infasurf to a certain level. ${ }^{*} p<0.05$ of comparison to the compressibility of pure Infasurf control.

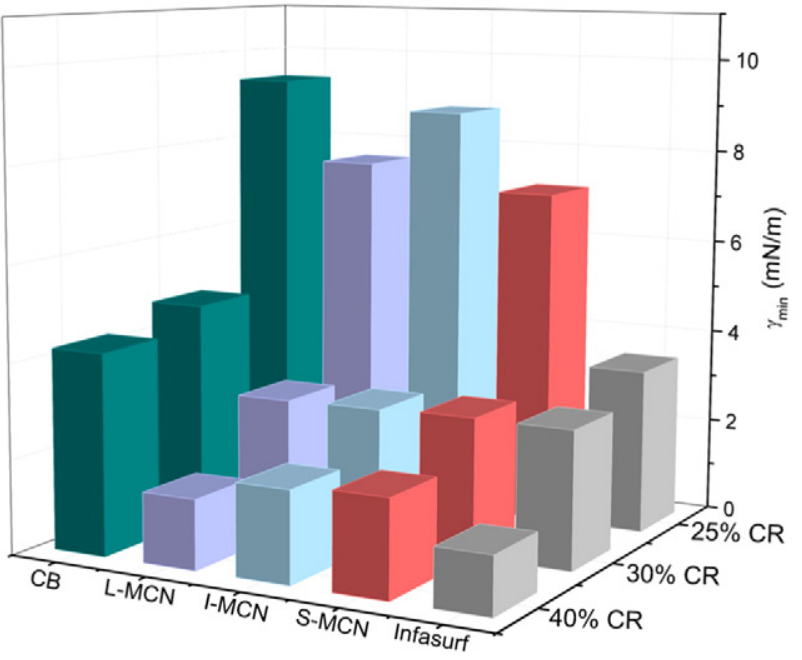

Fig. 4 - Minimum surface tension $\left(\gamma_{\min }\right)$ (the 10th cycle) as a function of compression ratios $(25 \%, 30 \%$, and $40 \%$, respectively).

It should be noted that the $\gamma_{\min }$ at $40 \%$ CR corresponded to the collapse surface tension of the surfactant film, indicated by a horizontal plateau at the end of compression (Appendix A Fig. S1). The collapse surface tension represented the absolute $\gamma_{\min }$ of the surfactant film because further increasing CR did not reduce the $\gamma_{\min }$. Hence, the $\gamma_{\min }$ at $40 \%$ CR was indicative to the inhibition potential of the exposed nanomaterials. It can be seen that exposure to MCNs of 3 different sizes all increased the $\gamma_{\text {min }}$ $(p<0.05)$, revealing significant surfactant inhibition. However, no statistically significant differences were found in the inhibition potential among $3 \mathrm{MCN}$ sizes tested here $(p>0.05)$.

It is worth noting that upon $40 \% \mathrm{CR}$, the CB also increased the $\gamma_{\min }$ of Infasurf from $\sim 1 \mathrm{mN} / \mathrm{m}$ to close to $4 \mathrm{mN} / \mathrm{m}$, manifesting surfactant inhibition. Our previous study showed that airborne multiwalled carbon nanotubes (MWCNTs) and graphene nanoplatelets (GNPs) at aerosol concentrations above a few tens $\mu \mathrm{g} / \mathrm{m}^{3}$ were able to significantly inactivate the biophysical function of Infasurf (Valle et al., 2015). Taking together, our results of MCNs, CB, MWCNTs and GNPs consistently demonstrated the inhibition potential of carbonaceous nanomaterials on the natural pulmonary surfactant. Such an adverse biophysical effect appears to be nonspecific, and is likely related to the strong hydrophobicity and porous nature of the carbonaceous nanomaterials (Valle et al., 2015).

\subsection{L-MCNs induced more cytotoxicity than I-MCNs and S-MCNs}

After passing the initial host defense line of the pulmonary surfactant, invading particles reach the alveoli to interact with alveolar epithelial cells and resident macrophages (Xia et al., 2016). Here, we determined the cytotoxicity of MCNs to J774A.1 macrophages and A549 lung epithelial cells. As shown in Fig. $5 \mathrm{a}$, the CCK-8 assay indicated that all MCNs at $\geq 20 \mu \mathrm{g} / \mathrm{mL}$ caused significant toxicity to J774A.1 cells with more than $20 \%$ reduction of cell viability $(p<0.05)$. Importantly, a pronounced size-dependent decline of cell viability was observed from S-MCNs to I-MCNs and L-MCNs at all concentrations (Fig. 5a, 
$p<0.05)$. In support of this finding, a size-dependent increase of extracellular LDH release was found, especially in cells treated with 3 sized MCNs at 80 and $160 \mu \mathrm{g} / \mathrm{mL}$ (Fig. 5b, $p<0.05$ ). Furthermore, remarkable cellular morphological alterations were visualized, as MCN-treated cells lost the macrophagic characteristic structure: surface protrusions, relative to untreated cells (Fig. 5c, denoted by yellow arrows). As a result, MCN-treated cells became rounder and harbored marked cell membrane collapse in the cellular body (Fig. 5c). These morphological alterations were more severe in L-MCN-treated cells than S-MCN- and I-MCN-treated cells (Fig. 5c). Meanwhile, we evaluated the cytotoxicity of these MCNs to A549 cells. Similar to the results of J774A.1 cells, all MCNs incurred significant toxicity to A549 cells starting at $10 \mu \mathrm{g} / \mathrm{mL}(p<0.05)$, and an apparent size-dependent toxicity was found from S-MCNs to I-MCNs and L-MCNs (Fig. 5d, $p<0.05$ ). These data together demonstrated that MCN exposure resulted in cytotoxicity to J774A.1 macrophages and A549 lung epithelial cells, and this toxic effect was closely associated with the size of MCNs, displaying a size-dependent increase of cytotoxicity.

Our previous studies demonstrated that nanoparticles entering the respiratory portal are immediately coated with a corona of the natural pulmonary surfactant (Fan et al., 2011; Hu et al., 2013; Valle et al., 2015). The pulmonary surfactant corona may determine the biological identity of the inhaled nanoparticles, and redefine their cytotoxicity and pro-inflammatory profiles (Monopoli et al., 2012). Here we tested this hypothesis by pre-incubating MCNs with Infasurf before running the cytotoxicity assays shown in Fig. 5a-d. As shown in Fig. 5e and f, pre-incubation with Infasurf remarkably reduced MCN-induced toxicity, as reflected by elevated cell viability and improved cellular morphology relative to treated cells without surfactant pre-incubation $(p<0.05)$. It indicates that the pulmonary surfactant corona formed on the surface of MCNs effectively reduced cytotoxicity of this nanomaterial, similar to the effect of surfactant made on silver nanoparticles (Sweeney et al., 2016; Theodorou et al., 2016).

Zinc nitrate was used in the synthesis of MCN materials, and the final mass of zinc was below $10 \%$ in MCNs, as characterized by energy dispersive X-ray spectroscopy (EDX) analysis. To this end, the zinc toxicity was further assayed. As shown in Fig. S2, zinc ions from 1.25 to $10 \mu \mathrm{g} / \mathrm{mL}$ (equivalent to that in MCNs from 12.5 to $100 \mu \mathrm{g} / \mathrm{mL}$ ) did not incur toxicity to cells. Since MCNs below $100 \mu \mathrm{g} / \mathrm{mL}$ were used in cell experiments in the current study, these results would rule out the contribution of zinc ions to MCN-induced cytotoxicity. Additionally, CTAB was also used the synthesis of MCNs. However, CTAB would decompose at $250^{\circ} \mathrm{C}$ (Chen et al., 2013; Holzinger et al., 2001). Since a condition of $800^{\circ} \mathrm{C}$ was used during MCN synthesis, there would no residual $C T A B$ left in synthesized materials, excluding the contribution of CTAB to MCN-induced cytotoxicity.

Since macrophages are the most cardinal phagocytes to ingest invading particles (Ma et al., 2016, 2017), we therefore investigated the intracellular accumulation of MCNs. As shown in Fig. 5c, MCN localization could be visualized in treated cells, as characterized by the dark dots (indicted by blue arrows). In contrast, no such dark dots could be found in untreated cells (Fig. 5c). To substantiate this observation, TEM was carried out. As shown in Fig. 6, TEM imaging corroborated the intracellular accumulation of MCNs. MCNs were visualized in the cytosol (mostly within membrane bound structures, namely phagosomes, as indicted in the enlarged images) in J774A.1 cells upon S-MCNs, I-MCNs and L-MCNs, analogous to previous findings (Kostarelos et al., 2007). To this end, we would assume that the intracellular accumulation of MCNs compromised the macrophagic morphology as evidenced by cell membrane collapse and loss of protrusions, similar to our recent report on GO materials (Qu et al., 2013). To better delineate the mechanisms underlying MCN-induced biological effects, we endeavored to avoid dramatic cell death by using relatively low concentrations in the following experiments that have a strong relevance to environmental exposure.

\subsection{Oxidative stress contributed to $\mathrm{MCN}$-induced cytotoxicity}

It is known that the uptake of foreign particles by macrophages generally leads to oxidative stress by promoting ROS production (Nel et al., 2006; Qu et al., 2013). Thus, intracellular ROS production was assayed in macrophages upon exposure of MCNs through FACS analysis. As shown in Fig. 7a, ROS production was greatly enhanced in J774A.1 cells treated with S-MCNs, I-MCNs and L-MCNs after exposure for 1 and $6 \mathrm{hr}$ at 5 and $10 \mu \mathrm{g} / \mathrm{mL}$, relative to the untreated cells (Fig. 7a and b, $p<0.001)$. Although L-MCNs triggered greater ROS production than S-MCNs and I-MCNs, the difference among the 3 MCNs was marginal for the treatment at $5 \mu \mathrm{g} / \mathrm{mL}$ for $1 \mathrm{hr}$. In contrast, a more pronounced difference was observed for cells treated with MCNs at $10 \mu \mathrm{g} / \mathrm{mL}$, revealing an obvious size-dependency (Fig. 7a, $p<0.05$ ). A similar size-dependent induction of ROS generation was demonstrated in J774A.1 cells post MCNs exposure for $6 \mathrm{hr}$ at both 5 and $10 \mu \mathrm{g} / \mathrm{mL}$ (Fig. 7b, $p<0.05$ ). These data together demonstrated that MCNs stimulated remarkable ROS production in J774A.1 cells, indicating significant oxidative stress, and the generation of ROS was closely related to the different sizes of the MCNs.

Oxidative stress has been recognized as the most important mechanism responsible for nanomaterial-induced toxicity to various cells including macrophages (Li et al., 2008; Xia et al., 2006). As a surrogate of oxidative stress, ROS is an crucial executor of cytotoxicity caused by nanomaterials including carbon nanomaterials (Garza et al., 2008; Nishanth et al., 2011). To verify that ROS contributed to MCN-associated toxicity, we pre-treated cells with a potent ROS scavenger, NAC (N-acetyl-cysteine), which is functioned to quench the intracellular ROS. As shown in Fig. 7c, NAC pre-treatment greatly quenched the ROS production by more than $30 \%$ with or without L-MCNs treatment, relative to cells without NAC pre-treatment (Fig. 7c, $p<0.05$ ), suggesting a robust ability of NAC to remove cellular ROS. As a consequence of diminished cellular ROS generation, L-MCN-induced cytotoxicity was significantly reversed, as evidenced by an over 35\% increase of live cell number upon NAC pre-treatment, compared to that without NAC pre-treatment (Fig. 7d, $p<0.05$ ). Taken together, these data suggested that MCN-induced cytotoxicity was attributed (at least partially) to oxidative stress.

\subsection{MCNs triggered pro-inflammatory responses of macrophages}

The above data showed that MCNs could bring about a sizedependent cytotoxicity, and the most significant difference was demonstrated between S-MCNs and L-MCNs. Thus, we 

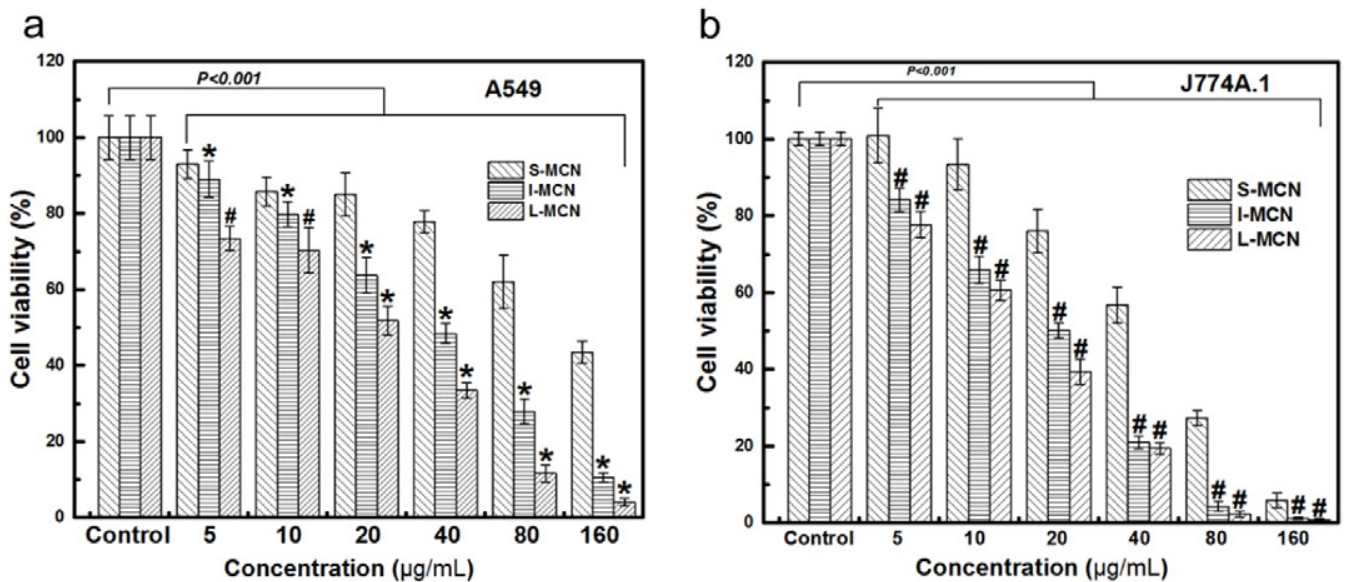

$\mathrm{C}$

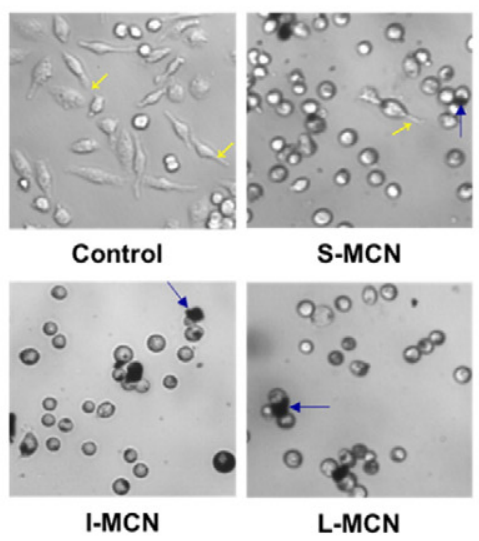

d

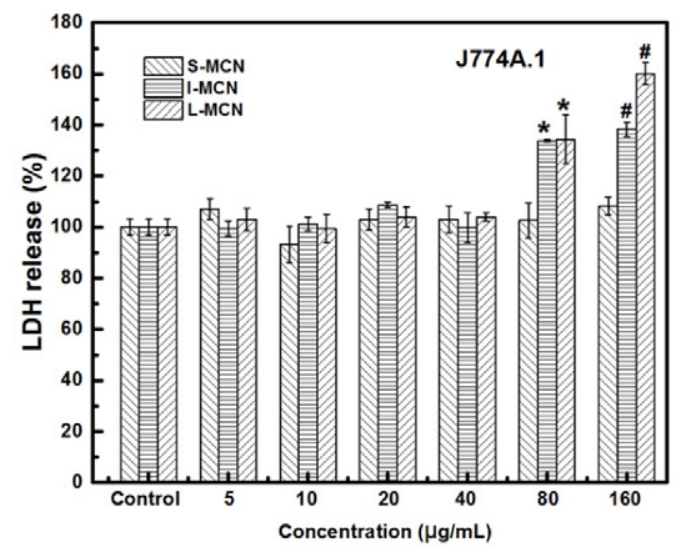

e
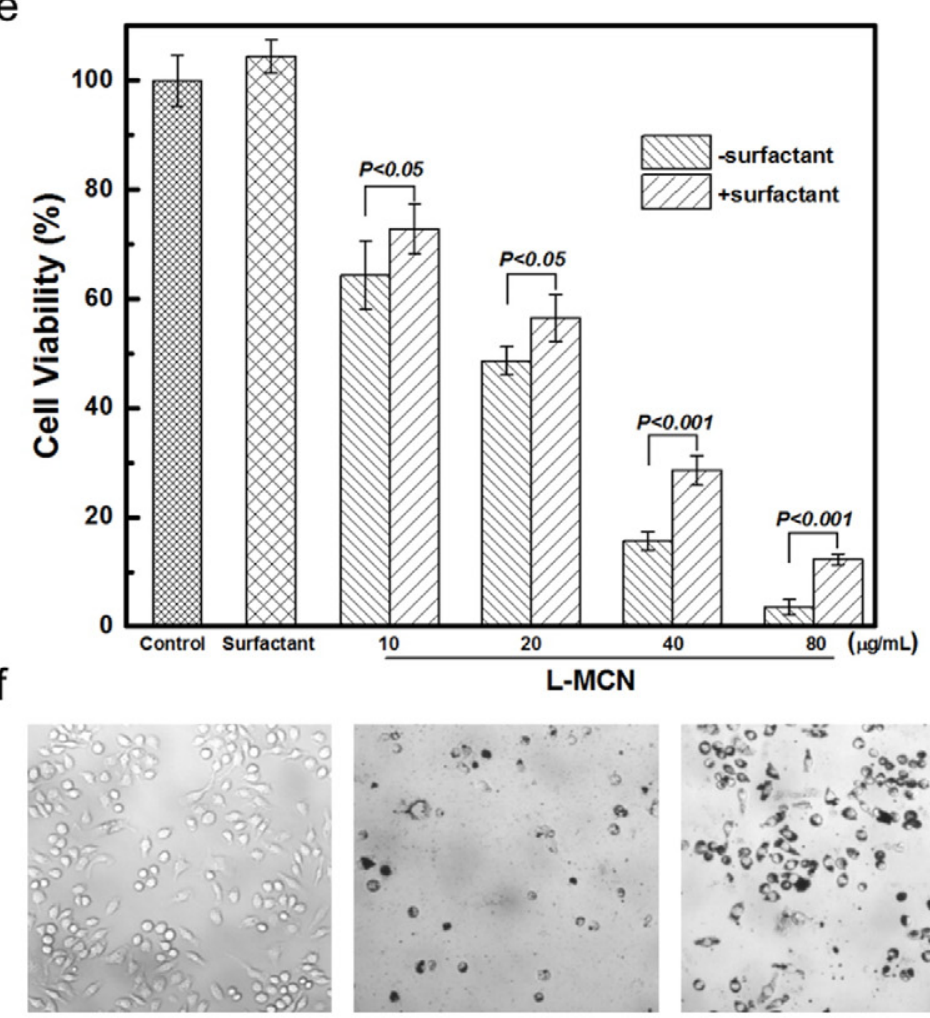

Control

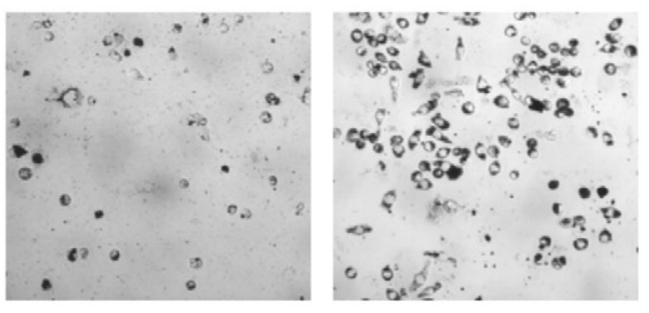

-Surfactant +Surfactant 
Fig. 5 - Cell viability and morphological alterations upon MCNs. (a) Viability of J774A.1 cells was assessed with the CCK-8 assay upon exposure to MCNs for $24 \mathrm{hr}$ at indicated concentrations $(n=6)$. (b) Relative extracellular LDH concentrations from cells treated with MCNs at various concentrations for $24 \mathrm{hr}(n=6)$. (c) Phase-contrast images showing cell morphological changes of J774A.1 cells after treatment with S-MCNs, I-MCNs and L-MCNs at $80 \mu \mathrm{g} / \mathrm{mL}$ for $24 \mathrm{hr}$. Yellow arrows indicate macrophagic protrusions, and blue arrow denote intracellular localization of MCNs. The original magnification, $\times 100$. (d) Viability of A549 cells was determined through the CCK-8 assay responding to MCNs for $24 \mathrm{hr}$ at various concentrations $(n=6)$. (e-f) Cell viability assay of J774. A1 cells after treatment with L-MCNs at various concentrations with or without surfactant pre-incubation. Prior to exposure, $100 \mu \mathrm{g}$ L-MCNs and $100 \mu \mathrm{g}$ surfactant were mixed in phosphate buffered solution (PBS), and incubated at a shaker at $4^{\circ} \mathrm{C}$ for $4 \mathrm{hr}$, followed by centrifugation to collect L-MCNs with surfactant adsorption. The collected L-MCNs were re-suspended in PBS and used for cell treatment for CCK-8 determination $(e)(n=6)$ and cell morphology imaging $(f)$. The original magnification, $\times 100$. The surfactant at $100 \mu \mathrm{g} / \mathrm{mL}$ also was used as a control for cell viability in (e). ${ }^{*} p<0.05 ;{ }^{\#} p<0.001$, compared to S-MCNs.

interrogated the differences between S-MCNs and L-MCNs in the following experiments. Our recent studies uncovered that an activate interaction between carbon nanomaterials and macrophages would indeed activate macrophages to a pro-inflammatory priming state (Ma et al., 2015, 2016, 2017; Xu et al., 2016). Since we observed a significant interaction of MCNs with J774A.1 cells, we postulated that MCNs were also able to activate these cells. To test this hypothesis, we investigated the pro-inflammatory responses of J774A.1 cells responding to MCNs by measuring the induction of inflammatory cytokines, TNF- $\alpha$ and IL-6. As shown in Fig. $8 \mathrm{a}$, an increased expression (by 30\%-40\% induction) was found for TNF- $\alpha$ in J774A.1 cells treated with S-MCNs and L-MCNs at $40 \mu \mathrm{g} / \mathrm{mL}(p<0.05)$. Similar findings were observed for IL-6 in J774A.1 cells treated with S-MCNs and L-MCNs (Fig. 8b, $p<0.05)$. Considering the effect of size, there was no a significant size-dependent increase of TNF- $\alpha$ and IL- 6 mRNA expression between S-MCNs and L-MCNs. These data together demonstrated that MCNs activated macrophages to induce inflammatory cytokines.

\subsection{MCNs induced inflammation and lung fibrosis in mice}

Experimental data have revealed that inhalation is the most common way to expose to airborne nanomaterials (Xia et al.,
2016), and nanomaterials with a large specific surface area (such as GO and carbon nanotubes) are more prone to induce lung injury (Ma et al., 2015, 2016, 2017; Xu et al., 2016). Therefore, we examined the effects of MCN exposure in the lung through oropharyngeal aspiration (i.t.) at the dose of $2 \mathrm{mg} / \mathrm{mL}$ for 1 and 7 days. As shown Fig. 9a, lung exposure of L-MCNs by i.t. instillation triggered great systemic inflammation after 1 day, as evidenced by $>1.5$ fold increase of white blood cell (WBC) count in the peripheral blood, relative to untreated mice $(p<0.05)$. By contrast, S-MCNs did not significantly increase the WBC count (Fig. 9a, $p>0.05$ ). Similar to the 1-day administration, MCNs stimulated the number of WBCs in peripheral blood after 7-day exposure, especially in L-MCN-treated mice (Fig. 9b, $p<0.05)$. In agreement with this result, the TNF- $\alpha$ levels in sera were increased by $18 \%$ upon L-MCN administration for 1 day, compared to untreated mice (Fig. 9c). As for the 7-day exposure, the serum TNF- $\alpha$ level was increased by approximately 2 folds in S-MCN- and L-MCN-treated mice, especially for L-MCN-treated mice, compared with untreated mice (Fig. 9d, $p<0.05$ ). These data together suggested that MCNs instigated systemic inflammatory responses in mice upon i.t. exposure of MCNs, especially for L-MCNs.

Afterwards, we looked into the lung injuries in mice challenged by MCNs. As reflected by the H\&E staining results, S-MCNs and L-MCNs caused alveolar wall thickening, filtration
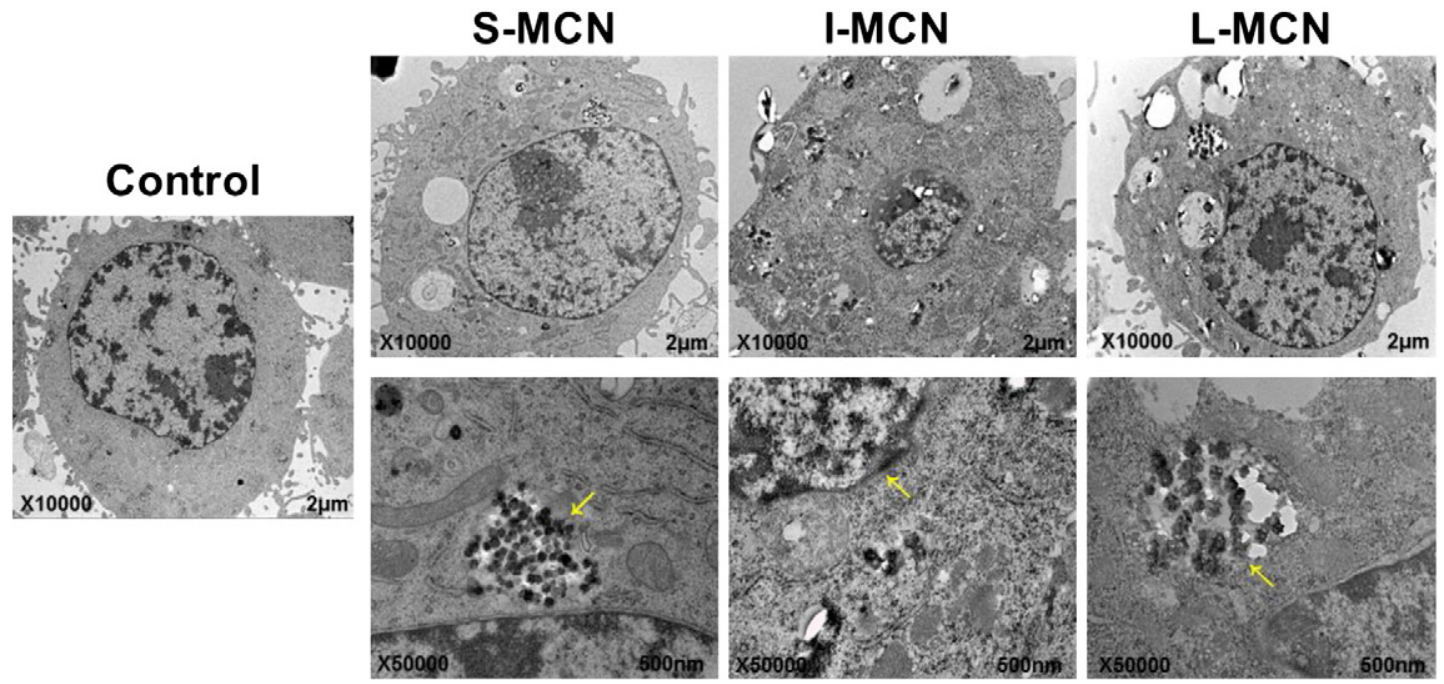

Fig. 6 - Localizations of MCNs inside cells. TEM images of J774A.1 cells treated with $30 \mu \mathrm{g} / \mathrm{mL} \mathrm{MCNs} \mathrm{for} 6 \mathrm{hr}$. Intracellular localization of MCNs inside phagosomes were shown in the enlarged images (lower panel, indicated by arrows) from the dash line squares. 
$1 \mathrm{hr}$
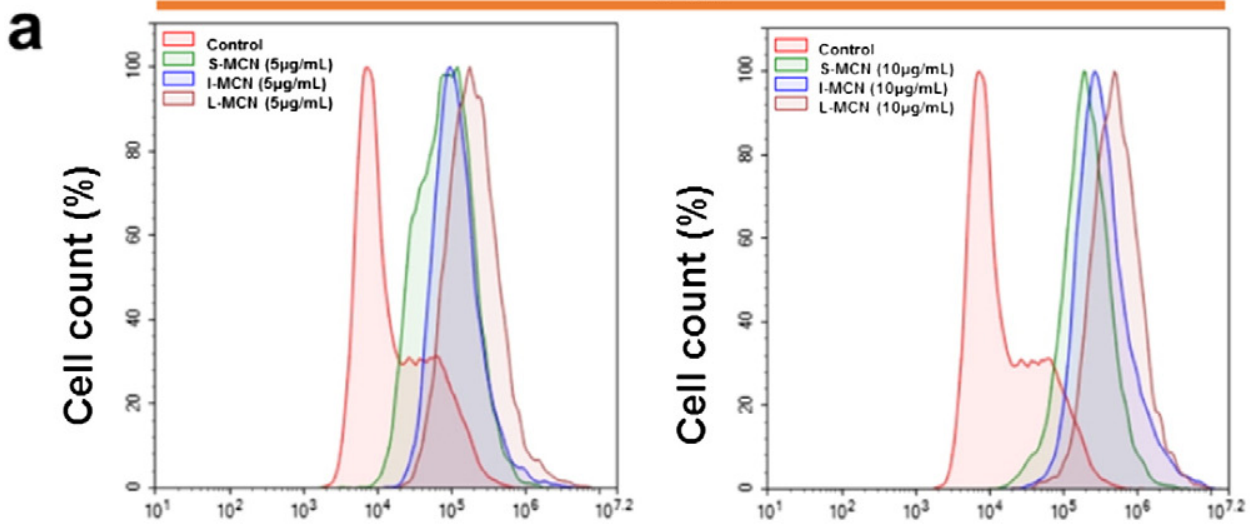

b

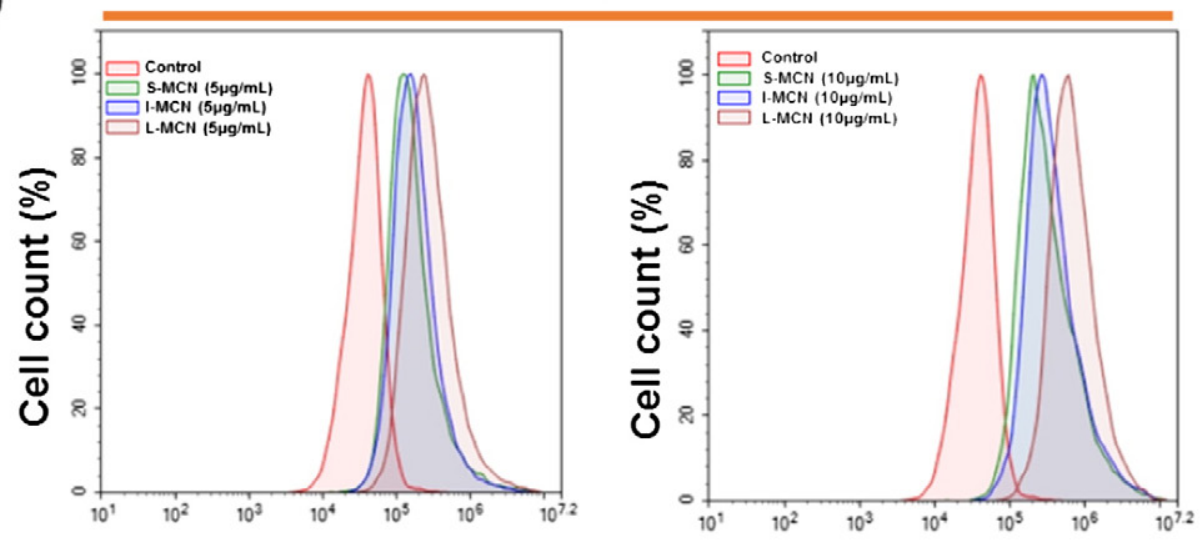

C
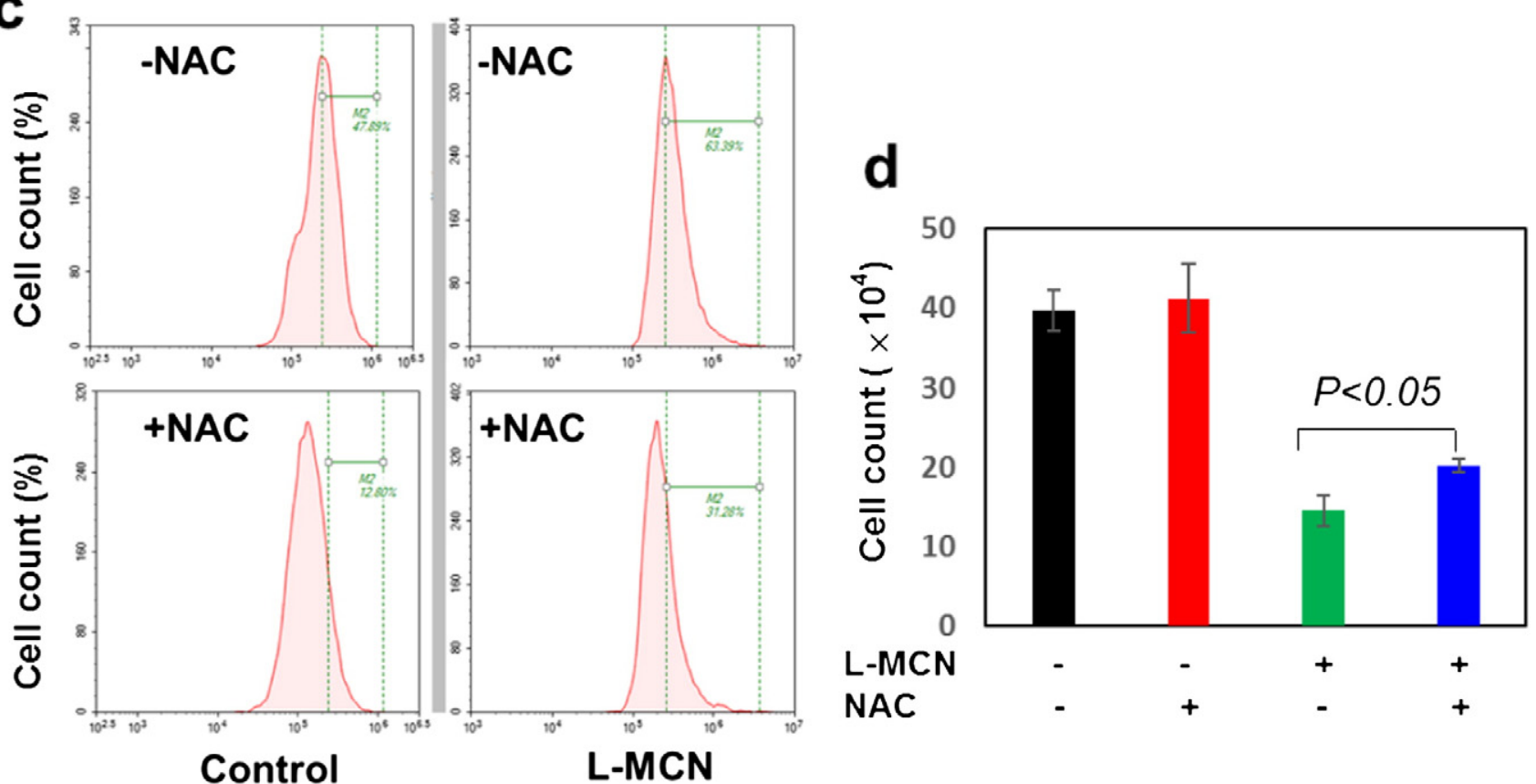

Fig. 7 - MCNs triggered a burst of ROS generation. (a) Relative intracellular ROS levels were determined by dichlorofluorescein (DCF) fluorescence intensities through flow cytometry (FACS) analysis in J774A.1 cells in response to MCNs at 5 and $10 \mu \mathrm{g} / \mathrm{mL}$ for 1 and $6 \mathrm{hr}(n=4)$. (b) Relative ROS levels in L-MCN-treated cells with or without N-acetyl-cysteine (NAC) pretreatment $(n=$ 4). (c) Cell number counting of cells treated with L-MCNs at $40 \mu \mathrm{g} / \mathrm{mL}$ for $12 \mathrm{hr}$ with or without NAC pretreatment ( $n=4$ ). After cells were collected, cells were stained with Trypan blue to exclude dead cells. Cell numbers were counted with a hemocytometer. 
a

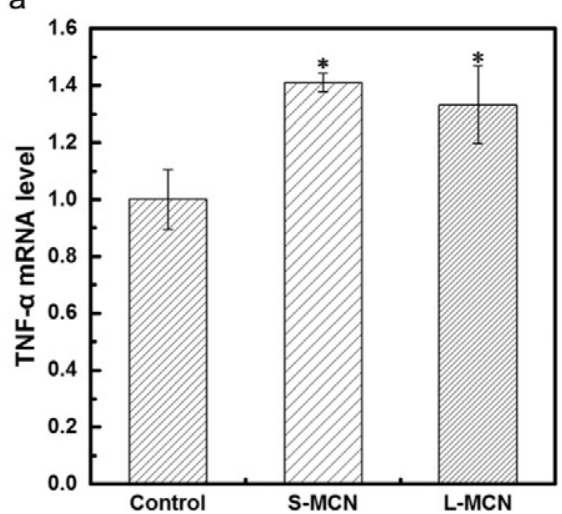

b

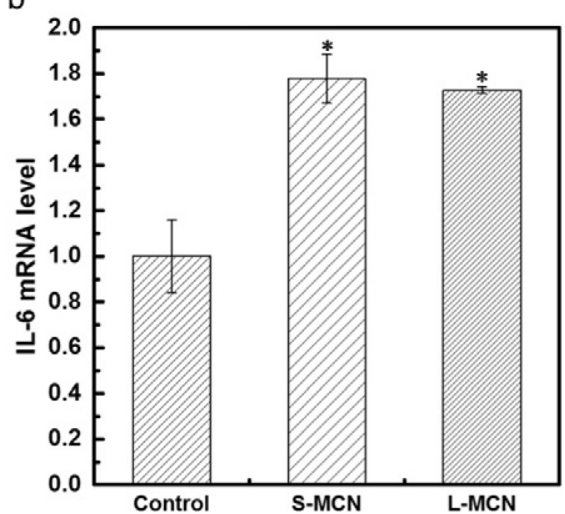

Fig. 8 - Macrophagic activation induced by MCNs. The expression levels of TNF- $\alpha$ mRNA (a) and IL-6 mRNA (b) were assessed in J774A.1 cells treated with MCNs at $40 \mu \mathrm{g} / \mathrm{mL}$ for $24 \mathrm{hr}(n=4) .{ }^{*} p<0.05$, compared to untreated control. TNF: tumor necrosis factor; mRNA: messenger ribonucleic acid.

of inflammatory cells and collagen accumulation in bronchioles and alveoli, especially for mice treated with MCNs for 7 days, compared to untreated mice (Fig. 10a). Meanwhile, collapse of lung alveoli was observed in mice treated with L-MCNs for
7 days (enlarged image, Fig. 10a), indicating significant pulmonary surfactant inhibition as predicted by our in vitro biophysical studies (Figs. 2-4). The important aspect of inflammatory responses to pathogenic particles is associated with the a

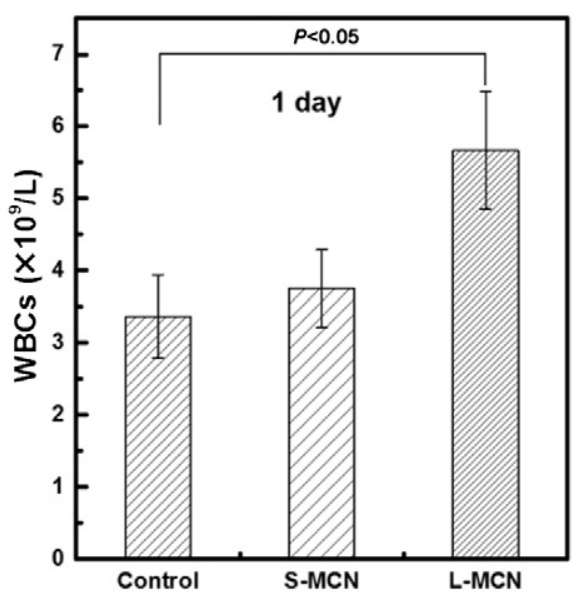

C

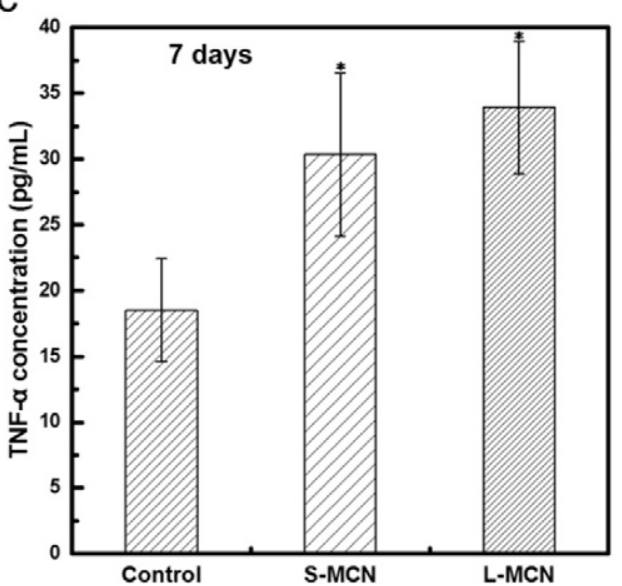

b

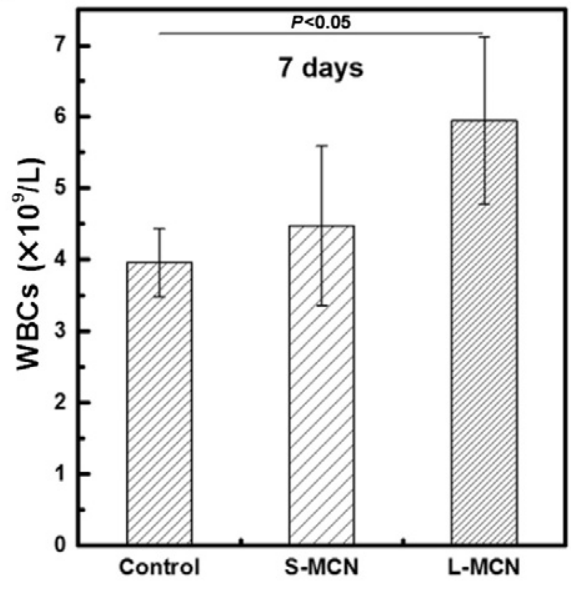

d

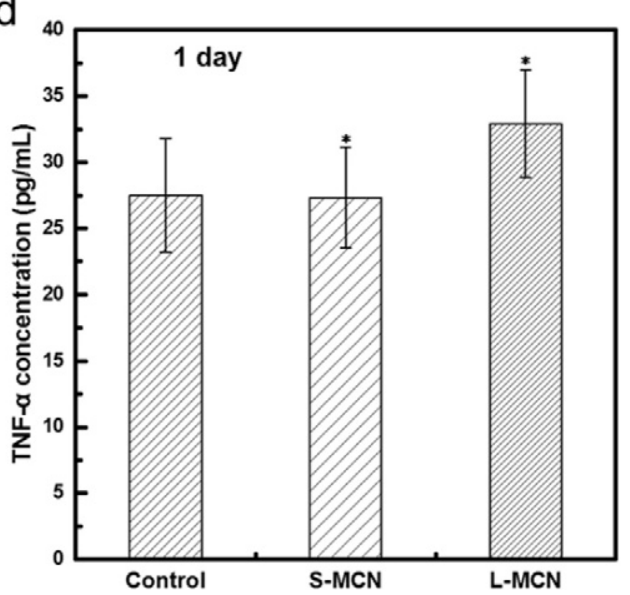

Fig. 9 - Systemic inflammation induced by MCNs in mice. Mice $(n=4)$ were administrated with MCN materials for 1 and 7 days. Thereafter, a series of assays were performed. White blood cell (WBC) counts in mice after exposure for 1 day (a) and 7 days (b). Serum concentrations of (b) TNF- $\alpha$ in mice post exposure for 1 day (b) and 7 days (d). ${ }^{*} p<0.05$, compared to untreated control. 
recruitment of inflammatory cells (Borregaard, 2010; Chavakis, 2012). Consistent with our previous findings on GO and carbon nanotubes (Ma et al., 2015, 2016, 2017; Xu et al., 2016), the bronchioles and alveoli, as the exposure site, were infiltrated with inflammatory cells (Fig. 10a, denoted by arrows), indicative of enhanced recruitment of inflammatory cells to the exposure site.

To define the elevated synthesis of collagen bronchioles and alveoli, Masson's trichrome staining was performed in lung sections. As manifested by the enhanced staining (in blue, indicated by arrows) in lungs from MCN-administrated mice, collagen accumulation was evident, especially for L-MCN-treated mice, diagnostic of lung fibrosis (Fig. 10b). This change was more obvious in L-MCN-treated mice for 7 days than that in L-MCN-treated mice for 1 day (Fig. 10b). Furthermore, to substantiate the occurrence of lung fibrosis, we probed the mass of $\alpha$-SMA. Enhanced mass of $\alpha$-SMA is an established surrogate of excessive deposition of the extracellular

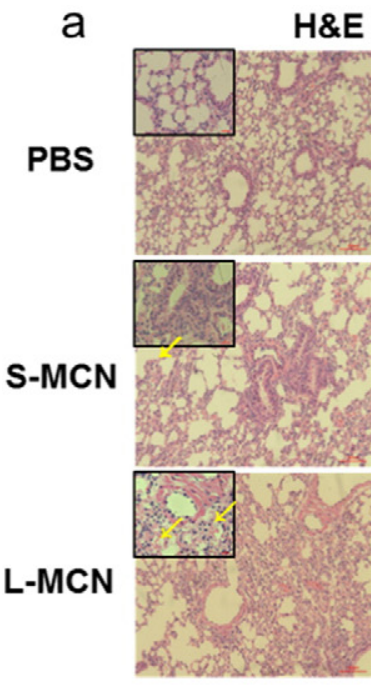

1 day

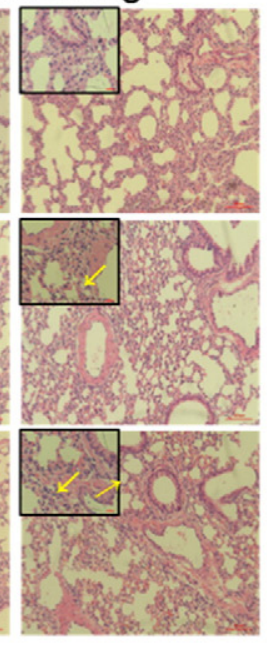

7 days b

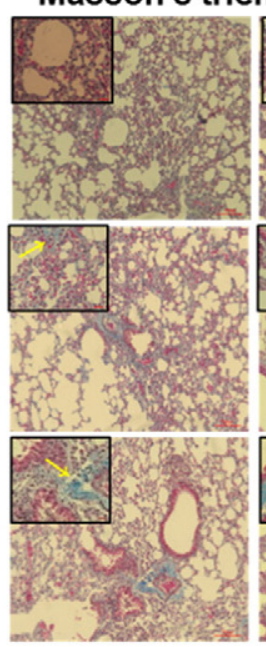

1 day

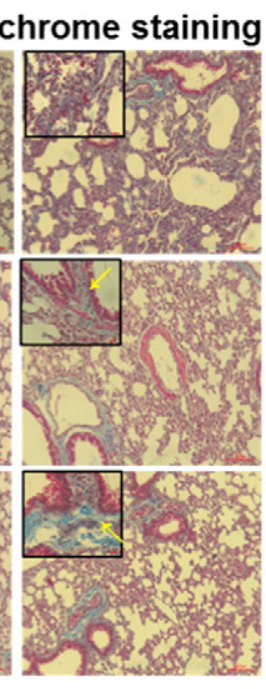

7 days

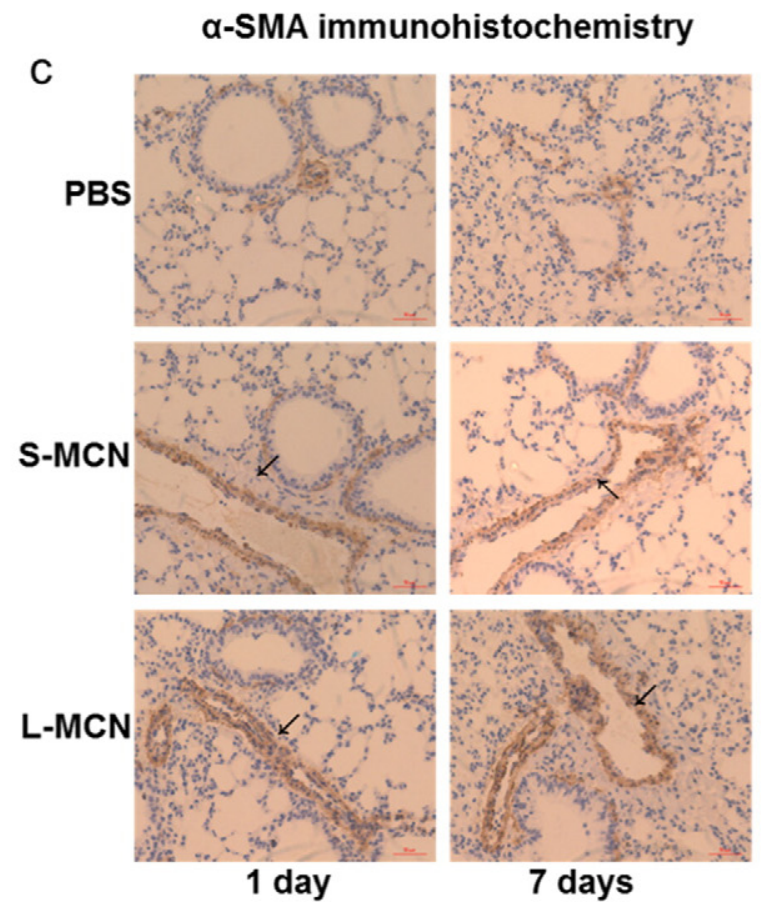

Fig. 10 - Lung inflammation and fibrosis in mice upon exposure to MCNs. (a) Hematoxylin-Eosin (H\&E) staining (arrows denote inflammatory cells) and (b) Masson's trichrome staining (blue color indicates collagen in the lung) of lung sections from mice treated with MCNs for 1 and 7 days. Original magnification, $\times 100$. Enlarged images show pulmonary alveoli from the line squares (Original magnification, $\times 400$ ). (c) Immunohistochemical analysis of alpha-smooth muscle actin ( $\alpha$-SMA) in lung sections. Arrows indicate positive staining of $\alpha$-SMA. Original magnification, $\times 200$. 
matrix during lung fibrosis (Desmouliere, 1995; Perdue and Brody, 1994; Zhang et al., 1996). The immunohistochemical analysis manifested increased content of $\alpha$-SMA in the lung sections of MCN-treated mice, relative to untreated mice (Fig. 10c).

Particle size is an important determinant for their bioreactivity in vitro and in vivo (Jiang et al., 2008; Silva et al., 2014). In other words, nanomaterials with different sizes may elicit distinct biological effects (Kostarelos and Novoselov, 2014; Servant et al., 2014). For instance, a size-dependent pattern for cytotoxicity and cellular uptake was observed in a few cell types, including alveolar epithelial cells, mesenchymal stem cells and macrophages (Akhavan et al., 2012; Chang et al., 2011; Matesanz et al., 2013; Yue et al., 2012). Similarly, here we observed enhanced infiltration of inflammatory cells and fibrosis in L-MCN-treated mice in comparison to S-MCNtreated mice (Fig. 10), revealing a size-dependent damage to the lung by MCNs.

\section{Conclusions}

In the current study, we uncovered the comprehensive toxicological profile of MCNs in the lung under the scenario of moderate environmental exposure. MCNs were found to induce biophysical inhibition of pulmonary surfactant, even at a low concentration of $10 \mu \mathrm{g} / \mathrm{mL}$. Inhibition of pulmonary surfactant increased the alveolar surface tension, thus leading to severe alveolar collapse observed in mice exposure to the MCNs. Furthermore, MCNs at low concentrations compromised the viability of J774A.1 macrophages and lung epithelial A549 cells. Incubating with nature pulmonary surfactant effectively reduced the cytotoxicity of MCNs. Regarding the pro-inflammatory responses, MCNs triggered macrophage activation in vitro, and also provoked lung inflammation in mice after inhalation exposure, coupled with lung fibrosis. Importantly, we found that the size of MCNs plays a significant role in regulating cytotoxicity and the pro-inflammatory potential of MCNs. Although no statistically significant size-dependence was observed with their biophysical inhibition potential on natural pulmonary surfactant, we found that larger MCNs in general induced more pronounced cytotoxicological effects than their smaller counterparts. The mechanism of the MCN-induced cytotoxicity was partially attributed to ROS generation. Taken together, here we demonstrated the comprehensive toxicological profile of MCNs in the lung, i.e., inhibiting pulmonary surfactant, inducing cytotoxicity, and triggering lung inflammation and fibrosis. Our results further suggested that fine-tuning the size of MCNs could be a practical precautionary design strategy to increase safety and biocompatibility of MCNs.

\section{Competing interests}

There is no potential conflict of interests to disclose.

\section{Acknowledgments}

We thank Dr. Walter Klein at ONY Inc. for donation of Infasurf samples. This work was supported by a grant under the National
“973" program (No. 2014CB932000), the Strategic Priority Research Program of the Chinese Academy of Sciences (No. XDB14000000), grants from the National Natural Science Foundation of China (Nos. 21425731 and 21637004), National Science Foundation No. CBET-1604119 (Yi Y. Zuo), and the Leahi Fund to Treat \& Prevent Pulmonary Diseases \#16ADVC-78729 from the Hawaii Community Foundation (Yi Y. Zuo).

\section{Appendix A Supplementary data}

Additional experimental results related to this work are provided online at https://doi.org/10.1016/j.jes.2017.08.018.

\section{R E F E R E N C E S}

Akhavan, O., Ghaderi, E., Akhavan, A., 2012. Size-dependent genotoxicity of graphene nanoplatelets in human stem cells. Biomaterials 33 (32), 8017-8025.

Allouni, Z.E., Cimpan, M.R., Høl, P.J., Skodvin, T., Gjerdet, N.R., 2009. Agglomeration and sedimentation of $\mathrm{TiO}_{2}$ nanoparticles in cell culture medium. Colloids Surf. B: Biointerfaces 68 (1), 83-87.

Bachofen, H., Schurch, S., Urbinelli, M., Weibel, E., 1987. Relations among alveolar surface tension, surface area, volume, and recoil pressure. J. Appl. Physiol. 62 (5), 1878-1887.

Beck-Broichsitter, M., Ruppert, C., Schmehl, T., Guenther, A., Betz, T., Bakowsky, U., et al., 2011. Biophysical investigation of pulmonary surfactant surface properties upon contact with polymeric nanoparticles in vitro. Nanomedicine 7 (3), 341-350.

Borregaard, N., 2010. Neutrophils, from marrow to microbes. Immunity 33 (5), 657-670.

Chang, Y., Yang, S.T., Liu, J.H., Dong, E., Wang, Y., Cao, A., et al., 2011. In vitro toxicity evaluation of graphene oxide on A549 cells. Toxicol. Lett. 200 (3), 201-210.

Chavakis, T., 2012. Leucocyte recruitment in inflammation and novel endogenous negative regulators thereof. Eur. J. Clin. Investig. 42 (6), 686-691.

Chen, J., Zhang, R., Han, L., Tu, B., Zhao, D., 2013. One-pot synthesis of thermally stable gold@ mesoporous silica core-shell nanospheres with catalytic activity. Nano Res. 6 (12), 871-879.

Desmouliere, A., 1995. Factors influencing myofibroblast differentiation during wound healing and fibrosis. Cell Biol. Int. 19 (5), 471-476.

Fan, Q., Wang, Y.E., Zhao, X., Loo, J.S., Zuo, Y.Y., 2011. Adverse biophysical effects of hydroxyapatite nanoparticles on natural pulmonary surfactant. ACS Nano 5 (8), 6410-6416.

Garza, K.M., Soto, K.F., Murr, L.E., 2008. Cytotoxicity and reactive oxygen species generation from aggregated carbon and carbonaceous nanoparticulate materials. Int. J. Nanomedicine 3 (1), 83-94.

Holzinger, M., Holzinger, M., Vostrowsky, O., Hirsch, A., Hennrich, F., Kappes, M., et al., 2001. Sidewall functionalization of carbon nanotubes. Angew. Chem. Int. Ed. Eng. 40 (21), 4002-4005.

Hu, G., Jiao, B., Shi, X., Valle, R.P., Fan, Q., Zuo, Y.Y., 2013. Physicochemical properties of nanoparticles regulate translocation across pulmonary surfactant monolayer and formation of lipoprotein corona. ACS Nano 7 (12), 10525-10533.

Jiang, W., Kim, B.Y., Rutka, J.T., Chan, W.C., 2008. Nanoparticle-mediated cellular response is size-dependent. Nat. Nanotechnol. 3 (3), 145-150.

Kim, T.-W., Chung, P.W., Slowing, I.I., Tsunoda, M., Yeung, E.S., Lin, V.S., 2008. Structurally ordered mesoporous carbon nanoparticles as transmembrane delivery vehicle in human cancer cells. Nano Lett. 8 (11), 3724-3727. 
Kostarelos, K., Novoselov, K.S., 2014. Materials science. Exploring the interface of graphene and biology. Science 344 (6181), 261-263.

Kostarelos, K., Lacerda, L., Pastorin, G., Wu, W., Wieckowski, S., Luangsivilay, J., et al., 2007. Cellular uptake of functionalized carbon nanotubes is independent of functional group and cell type. Nat. Nanotechnol. 2 (2), 108-113.

Lewis, J.F., Veldhuizen, R., 2003. The role of exogenous surfactant in the treatment of acute lung injury. Annu. Rev. Physiol. 65, 613-642.

Li, N., Xia, T., Nel, A.E., 2008. The role of oxidative stress in ambient particulate matter-induced lung diseases and its implications in the toxicity of engineered nanoparticles. Free Radic. Biol. Med. 44 (9), 1689-1699.

Lopez-Rodriguez, E., Pérez-Gil, J., 2014. Structure-function relationships in pulmonary surfactant membranes: from biophysics to therapy. Biochim. Biophys. Acta 1838 (6), 1568-1585.

Ma, J., Liu, R., Wang, X., Liu, Q., Chen, Y., Valle, R.P., et al., 2015. Crucial role of lateral size for graphene oxide in activating macrophages and stimulating pro-inflammatory responses in cells and animals. ACS Nano 9 (10), 10498-10515.

Ma, J., Li, R., Qu, G., Liu, H., Yan, B., Xia, T., et al., 2016. Carbon nanotubes stimulate synovial inflammation by inducing systemic pro-inflammatory cytokines. Nano 8 (42), 18070-18086.

Ma, J., Li, R., Liu, Y., Qu, G., Liu, J., Guo, W., et al., 2017. Carbon nanotubes disrupt iron homeostasis and induce anemia of inflammation through inflammatory pathway as a secondary effect distant to their portal-of-entry. Small 13 (15), 1603830

Maiorano, G., Sabella, S., Sorce, B., Brunetti, V., Malvindi, M.A., Cingolani, R., et al., 2010. Effects of cell culture media on the dynamic formation of protein-nanoparticle complexes and influence on the cellular response. ACS Nano 4 (12), 7481-7491.

Matesanz, M.C., Vila, M., Feito, M.J., Linares, J., Gonçalves, G., Vallet-Regi, M., et al., 2013. The effects of graphene oxide nanosheets localized on F-actin filaments on cell-cycle alterations. Biomaterials 34 (5), 1562-1569.

Monopoli, M.P., Aberg, C., Salvati, A., Dawson, K.A., 2012. Biomolecular coronas provide the biological identity of nanosized materials. Nat. Nanotechnol. 7 (12), 779-786.

Nel, A., Xia, T., Madler, L., Li, N., 2006. Toxic potential of materials at the nanolevel. Science 311 (5761), 622-627.

Nishanth, R.P., Jyotsna, R.G., Schlager, J.J., Hussain, S.M., Reddanna, P., 2011. Inflammatory responses of RAW 264.7 macrophages upon exposure to nanoparticles: role of ROS-NFkB signaling pathway. Nanotoxicology 5 (4), 502-516.

Perdue, T.D., Brody, A.R., 1994. Distribution of transforming growth factor-beta 1, fibronectin, and smooth muscle actin in asbestos-induced pulmonary fibrosis in rats. J. Histochem. Cytochem. 42 (8), 1061-1070.

Qu, G., et al., 2013. Graphene oxide induces toll-like receptor 4 (TLR4)-dependent necrosis in macrophages. ACS Nano 7, 5732-5745.

Sachan, A.K., Harishchandra, R.K., Bantz, C., Maskos, M., Reichelt, R., Galla, H.J., 2012. High-resolution investigation of nanoparticle interaction with a model pulmonary surfactant monolayer. ACS Nano 6 (2), 1677-1687.

Sandberg, W.J., Låg, M., Holme, J.A., Friede, B., Gualtieri, M., Kruszewski, M., Schwarze, P.E., et al., 2012. Comparison of non-crystalline silica nanoparticles in IL-1 $\beta$ release from macrophages. Part. Fibre Toxicol. 9, 32.

Schürch, S., Bachofen, H., Goerke, J., Green, F., 1992. Surface properties of rat pulmonary surfactant studied with the captive bubble method: adsorption, hysteresis, stability. Biochim. Biophys. Acta 1103 (1), 127-136.
Schürch, S., Green, F.H., Bachofen, H., 1998. Formation and structure of surface films: captive bubble surfactometry. Biochim. Biophys. Acta 1408 (2-3), 180-202.

Servant, A., Bianco, A., Prato, M., Kostarelos, K., 2014. Graphene for multi-functional synthetic biology: the last 'zeitgeist' in nanomedicine. Bioorg. Med. Chem. Lett. 24 (7), 1638-1649.

Silva, T., Pokhrel, L.R., Dubey, B., Tolaymat, T.M., Maier, K.J., Liu, X., 2014. Particle size, surface charge and concentration dependent ecotoxicity of three organo-coated silver nanoparticles: comparison between general linear modelpredicted and observed toxicity. Sci. Total Environ. 468, 968-976.

Sweeney, S., Leo, B.F., Chen, S., Abraham-Thomas, N., Thorley, A.J., Gow, A., et al., 2016. Pulmonary surfactant mitigates silver nanoparticle toxicity in human alveolar type-I-like epithelial cells. Colloids Surf. B Biointerfaces 145, 167-175.

Theodorou, I.G., Ruenraroengsak, P., Gow, A., Schwander, S., Zhang, J.J., Chung, K.F., et al., 2016. Effect of pulmonary surfactant on the dissolution, stability and uptake of zinc oxide nanowires by human respiratory epithelial cells. Nanotoxicology 10 (9), 1351-1362.

Valle, R.P., Huang, C.L., Loo, J.S., Zuo, Y.Y., 2014. Increasing hydrophobicity of nanoparticles intensifies lung surfactant film inhibition and particle retention. ACS Sustain. Chem. Eng. 2 (7), 1574-1580.

Valle, R.P., Wu, T., Zuo, Y.Y., 2015. Biophysical influence of airborne carbon nanomaterials on natural pulmonary surfactant. ACS Nano 9 (5), 5413-5421.

Vallet-Regí, M., Balas, F., Arcos, D., 2007. Mesoporous materials for drug delivery. Angew. Chem. Int. Ed. Eng. 46 (40), 7548-7558.

Wang, X., Xia, T., Ntim, S.A., Ji, Z., Lin, S., Meng, H., et al., 2011. Dispersal state of multiwalled carbon nanotubes elicits profibrogenic cellular responses that correlate with fibrogenesis biomarkers and fibrosis in the murine lung. ACS Nano 5 (12), 9772-9787.

Wang, X., Xia, T., Duch, M.C., Ji, Z., Zhang, H., Li, R., et al., 2012. Pluronic F108 coating decreases the lung fibrosis potential of multiwall carbon nanotubes by reducing lysosomal injury. Nano Lett. 12 (6), 3050-3061.

Wynn, T.A., Chawla, A., Pollard, J.W., 2013. Macrophage biology in development, homeostasis and disease. Nature 496 (7446), 445-455.

Xia, T., Kovochich, M., Brant, J., Hotze, M., Sempf, J., Oberley, T., et al., 2006. Comparison of the abilities of ambient and manufactured nanoparticles to induce cellular toxicity according to an oxidative stress paradigm. Nano Lett. 6 (8), 1794-1807.

Xia, T., Zhu, Y., Mu, L., Zhang, Z.F., Liu, S., 2016. Pulmonary diseases induced by ambient ultrafine and engineered nanoparticles in twenty-first century. Natl. Sci. Rev. 3 (4), 416-429.

Xu, G., Liu, S., Niu, H., Lv, W., Wu, R.A., 2014. Functionalized mesoporous carbon nanoparticles for targeted chemo-photothermal therapy of cancer cells under near-infrared irradiation. RSC Adv. 4, 33986-33997.

Xu, M., Zhu, J., Wang, F., Xiong, Y., Wu, Y., Wang, Q., et al., 2016. Improved in vitro and in vivo biocompatibility of graphene oxide through surface modification: poly(acrylic acid)-functionalization is superior to PEGylation. ACS Nano 10 (3), 3267-3281.

Yu, K., Yang, J., Zuo, Y.Y., 2016. Automated droplet manipulation using closed-loop axisymmetric drop shape analysis. Langmuir 32 (19), 4820-4826.

Yue, H., Wei, W., Yue, Z., Wang, B., Luo, N., Gao, Y., et al., 2012. The role of the lateral dimension of graphene oxide in the regulation of cellular responses. Biomaterials 33 (16), 4013-4021. 
Zhang, H., Gharaee-Kermani, M., Zhang, K., Karmiol, S., Phan, S.H., 1996. Lung fibroblast alpha-smooth muscle actin expression and contractile phenotype in bleomycin-induced pulmonary fibrosis. Am. J. Pathol. 148 (2), 527.

Zhang, H., Fan, Q., Wang, Y.E., Neal, C.R., Zuo, Y.Y., 2011. Comparative study of clinical pulmonary surfactants using atomic force microscopy. Biochim. Biophys. Acta 1808 (7), 1832-1842.
Zuo, Y.Y., Possmayer, F., 2007. How does pulmonary surfactant reduce surface tension to very low values? J. Appl. Physiol. 102 (5), 1733-1734.

Zuo, Y.Y., Veldhuizen, R.A., Neumann, A.W., Petersen, N.O., Possmayer, F., 2008. Current perspectives in pulmonary surfactant-inhibition, enhancement and evaluation. Biochim. Biophys. Acta 1778 (10), 1947-1977. 